\title{
Metodologias Ativas à Luz de Comenius: uma Experiência na Pós-Graduação
}

\author{
Andrea C. A. Almeida1, Carlos Ian B. Melo2, Myrcea S. S. Harvey2, Marcos \\ Vinicius A. Lima3, Pedro Jonatas S. Chaves5
}

1 Coordenação do Núcleo de Educação a Distância da Universidade de Fortaleza (UNIFOR) / Programa de Pós-Graduação em Educação da Universidade Estadual do Ceará (PPGE/UECE)

2 Programa de Pós-Graduação em Educação da Universidade Estadual do Ceará (PPGE/UECE)

3 Universidade Federal do Ceará - Laboratório Interdisciplinar de Computação e Engenharia de Software (LINCE) / Programa de Pós-Graduação em Educação da Universidade Estadual do Ceará (PPGE/UECE)

${ }_{4}$ Prefeitura Municipal de Itapipoca / Prefeitura Municipal de Uruburetama / Programa de Pós-Graduação em Educação da Universidade Estadual do Ceará (PPGE/UECE)

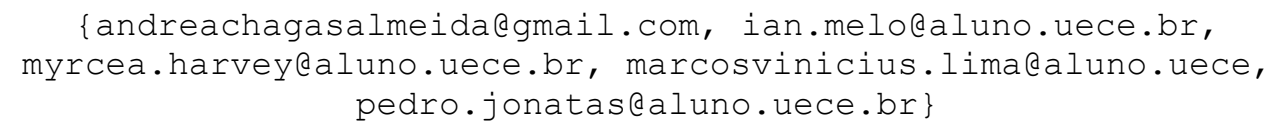

Abstract. This article aims to relate the ideas of the famous educator Jan Amos Comenius, dating from the 17th century, to the theory and practice of active methodologies, proposed to contemporary higher education. The main work of this author, Didatica Magna, and current studies on active methodologies was used as the theoretical basis. Methodologically, an experience report was carried out, confronting the concepts which were studied and the practice of an innovative class in higher education. As a conclusion, we point out that Comenius' postulates are imbricated with the active learning methodologies, since they demonstrate their potential to value the teacher's work and to provide the student with a more meaningful learning experience.

Resumo. Este artigo tem por objetivo relacionar as ideias do educador Jan Amos Comenius, que datam do século XVII, à teoria e prática das metodologias ativas, propostas à educação superior contemporânea. Como fundamento teórico utilizouse da principal obra desse autor, Didática Magna, e de estudos atuais sobre metodologias ativas. Metodologicamente optou-se pela realização de um relato de experiência, entrecruzando os conceitos estudados e a prática de uma aula inovadora no ensino superior. Como conclusões apontamos que os postulados de Comenius estão imbricados com as metodologias ativas, pois demonstram o 
potencial destas em valorizar o trabalho do professor e oportunizar o desempenho do aluno, proporcionando uma experiência de aprendizagem significativa.

\section{Introdução}

A proposta deste trabalho surge a partir da disciplina Teorias da Educação e Formação de Professores, componente curricular obrigatório dos cursos de Mestrado e Doutorado Acadêmico do Programa de Pós-graduação em Educação da Universidade Estadual do Ceará (PPGE/UECE). Tal disciplina teve por propósito resgatar as contribuições e postulados dos maiores teóricos da educação, tendo como marco inicial Comenius, considerado o pai da Didática, passando por nomes ilustres como Rousseau, Piaget, Dewey, Paulo Freire, Saviani, e outros, chegando à contemporaneidade.

Partindo desse contexto, o presente estudo busca fazer uma explanação acerca das ideias do educador e escritor Jan Amos Comenius, que datam do século XVII, relacionando-as à teoria e prática das metodologias ativas, propostas à educação superior contemporânea. Nos interessa compreender como as ideias desse teórico, associadas à didática e ao ensino, abordam e podem ser aplicadas às metodologias ativas propostas em uma educação inovadora no ensino superior.

Para tanto, o artigo articula-se como um relato de experiência, no qual se fará uso dos escritos de e sobre Comenius, e dos principais conceitos a respeito de metodologias ativas e ensino inovador, costurando esta tessitura a partir da experiência em uma aula ministrada sobre esse educador, ancorada em práticas não-tradicionais, na disciplina mencionada.

\section{Comenius e as metodologias ativas: qual a relação?}

Pensar em educação nos dias atuais tem sido um desafio, visto que esta vem sofrendo mudanças significativas em suas principais configurações, bem como nos paradigmas que a fundamenta. $\mathrm{O}$ aprender não mais vincula-se apenas às aulas presenciais $\mathrm{e}$ expositivas, mas sim a diversos aspectos sociais, estruturais e, sobretudo, funcionais, que demandam ações cada vez mais inovadoras, como as novas metodologias, instrumentos de avaliação, estratégias didáticas e recursos tecnológicos, para que seja possível, assim, atender um público cada vez mais diverso e exigente, no que tange a busca pela informação e conhecimento (MORAN, 2015).

É válido ressaltar que aprendemos ativamente e a todo momento, desde o nascimento e ao longo de toda vida. E esse aprendizado se dá por meio da educação formal (salas de aulas estruturadas para tal atividade), bem como com a educação informal, isto é, aprendemos com os mais velhos, aprendemos em situações concretas e em situações subjetivas, aprendemos quando falamos e quando ouvimos. E diante das novas tecnologias, aprendemos também com vídeos, músicas e, muito especialmente, com a própria internet.

Nesse sentido, no que tange à educação formal, temos como principal meio de aprendizado a transmissão oral, que tem como protagonista o professor, auxiliado por vezes de outros instrumentos. Entretanto, esse processo, que consolidou-se ao longo do tempo devido a sua importância (afinal, foi graças à tradição oral que a história foi-nos transmitida, e assim preservada), é, sobretudo, passivo. Passivo da perspectiva de que o formato constitui-se essencialmente de um professor que fala e de um aluno que ouve.

E diante desse cenário, nos últimos anos tem-se ouvido falar com mais frequência em novas abordagens de ensino, combinando as metodologias ativas em contextos educacionais formais, e isso tem acontecido, devido ao novo perfil dos 
estudantes que têm se modificado de maneira significativa. Nessa perspectiva, o trabalho do professor em sala de aula passa a ser cada vez mais considerado concreto e abstrato, como descrito por Almeida e Melo (2017):

Concreto, em virtude da sua utilidade em ensinar, transmitir, repassar,
estudar, pesquisar, formar. E abstrato, no sentido de lidar com estilos de
aprendizagem completamente diferentes, onde todos têm especificidades, as
quais tornam-se atividades com identidades muito próprias (p. 3).

Assim, em um período em que as tecnologias estão em voga, nunca se falou tanto em inovar nos processos educacionais, rever práticas, formar professores, buscar uma educação inovadora e colocar o aluno como protagonista do processo de ensinoaprendizagem. E é nesse ínterim, que surge a abordagem das metodologias ativas. Mas, afinal, o que são metodologias ativas?

Segundo Berbel (2011, p. 29) as metodologias ativas "[...] baseiam-se em formas de desenvolver o processo de aprender, utilizando experiências reais ou simuladas, visando às condições de solucionar, com sucesso, desafios advindos das atividades essenciais da prática social, em diferentes contextos". Para Moran $(2015$, p. 5) "nas metodologias ativas de aprendizagem, o aprendizado se dá a partir de problemas e situações reais; os mesmos que os alunos vivenciarão depois na vida profissional, de forma antecipada, durante o curso".

Nessa perspectiva, as metodologias ativas são utilizadas hoje como estratégia pedagógica com o foco do processo de ensino e aprendizagem no aprendiz. A proposta é criar situações educativas nas quais os estudantes façam coisas, coloquem conhecimentos em ação, pensem e conceituem o que fazem, ou seja, os alunos sejam os protagonistas da sua educação.

De acordo com Filatro e Cavalcanti (2018, p. 7), "as metodologias ativas se ancoram em uma visão mais humanista, menos tecnicista da educação, e são inspiradas por teóricos cujas teses foram erguidas em contraposição a modelos tradicionais vigentes".

Também entre as diversas estratégias utilizadas nas metodologias ativas observa-se a inserção do ensino híbrido, que de acordo com Horn e Staker (2015), possibilita atender às necessidades da geração atual de estudantes por meio de um sistema de ensino centrado neles, fazendo-se uso da personalização e aprendizagem baseada em competências. No ensino híbrido a sala de aula é expandida e o aluno aprenderá tanto de forma presencial como por meio do ensino on-line (ibid.).

Contudo, é possível perceber que, por mais que se discutam novas metodologias, novas propostas avaliativas e até novos recursos, a base teórica e pedagógica dessas iniciativas tem forte influência em nomes como Dewey, Vygotsky, Piaget, Freire e outros. Buscam beber das abordagens teóricas do cognitivismo, socioconstrutivismo e conectivismo, nas quais há uma articulação entre os aspectos ação-reflexão, elementos essenciais nas metodologias ativas.

Dado o cenário, é importante constatar a possibilidade de estabelecer relações entre os postulados e ideias defendidas por pensadores da antiguidade e as propostas inovadoras em educação. Evidenciamos aqui, especificamente, como objeto de nossa análise, os estudos de Jan Amos Comenius (1592-1670), a fim de inferirmos sobre suas contribuições para a discussão no campo educacional, servindo como bases fundamentais para o que se desenha atualmente como metodologias ativas.

No contexto do desenvolvimento do Sistema Capitalista na Alemanha e perseguições ao protestantismo por parte da Igreja Católica, Comenius surge afirmando 
que "[...] a causa das guerras e das chagas da humanidade é a ignorância humana, e o remédio para a cura será encontrado na educação de todos os povos" (DAMIS, 2012, p. 18). Com isso, propôs mudanças na escola da época, no ensino dogmático católico, na religião que gera guerras e, consequentemente, na sociedade desigual.

Sua mais expressiva contribuição foi a obra Didática Magna: tratado da arte universal de ensinar tudo a todos, escrita em 16511, em plena guerra dos 30 anos. Nesta obra, Comenius descreve a escola como um espaço onde os professores devem ensinar menos e os alunos aprender mais. O autor também sugere que as escolas sejam cenários de menos barulho, aversão, e trabalho sem proveito, mas antes seja um ambiente de mais lazer, alegria e sólido progresso.

$\mathrm{Na}$ introdução do seu livro, o autor define a didática ou discentia como a arte de ensinar tudo a todos (COMENIUS, 2012). De fato, essa definição pode contemplar várias interpretações pedagógicas e, à medida que lemos o livro Didática Magna, tornase mais simples compreender que uma das principais concepções da arte de ensinar é, na verdade, a busca incessante do docente em envolver o aluno e fazer com que este aprenda.

Outra interpretação para esse trecho implicaria dizer que a educação carece de homens (docentes) com objetivos claros e seguros, de maneira tal que o resultado não seja diverso daquele objetivo planejado com emprego de métodos válidos e disponíveis. Numa interpretação extensiva e numa perspectiva mais atual, entendemos que Comenius assevera aqui o papel fundamental que o professor possui como um formador capacitado e com expertise adequada - daí dizer que esse "homem", o docente, deve estar seguro (NUNES e NUNES, 2013).

Comenius (2012) esclarece ainda que todo aluno deve ter acesso à aprendizagem ao seu tempo e o conteúdo deve ser ministrado a partir de explicações mais simples que podem gradualmente tornar-se mais complexas, partindo do concreto para o abstrato. Para confirmar essa observação, o autor faz o remate com a assertiva textual que descreve que não devemos esperar que o aluno aprenda um determinado conteúdo de pronto, haja vista que nenhum indivíduo possivelmente aprende da mesma maneira ou ao mesmo passo que os demais. E isso é esperado no processo ensino-aprendizagem. Nas palavras do educador, "a semente deve brotar e crescer gradualmente"2 (COMENIUS, 2012, tradução nossa).

Segundo Nunes e Nunes (2013), as transformações pedagógicas atuam na ressignificação dos conceitos da práxis do professorado, devendo, assim, acompanhar as mudanças. Diferentemente de uma perspectiva dogmática, as práticas pedagógicas devem constantemente ser ressignificadas, ideia defendida também por Comenius, de maneira avant-garde à sua época, na qual predominava uma prática monolítica.

Seu objetivo principal é criar um método para ensinar todas as ciências, costumes e piedade, segundo a capacidade de cada indivíduo. Diante das transformações que o mundo passava naquele momento, a vida na cidade era diferente do meio rural, ou seja, novos padrões tinham que ser criados, uma vez que no feudo tudo era produzido e consumido de forma local. Entretanto o capitalismo e os estados nacionais surgiam, a essa altura, como uma possibilidade de mudança dessa dinâmica.

1 Para levar a presente discussão a cabo, utilizamos a obra original intitulada Didática Magna de Comenius que foi escrita pelo próprio autor em língua inglesa, cuja edição está no formato $e$-book (kindle) e foi lançada em 2012, razão pela qual utilizaremos essa referência temporal à obra.

2 Posição 99 de 6597. 
Para Comenius, mais importante do que "o que ensinar" é o "como e para que ensinar". Ou seja, a Didática para ele concentra-se no "como fazer", como técnica universal de ensino em todos os seus aspectos práticos e operacionais. Esta didática é instrumental, tendo como objetivo central "guiar, dirigir ou instrumentalizar o ensino e aprendizagem, embora possua preocupações quanto à organização, desenvolvimento, avaliação e, principalmente, inovação técnica.

De maneira clara e apascentadora, Comenius resume seus ensinamentos ressaltando que o professor que de fato ensina para atingir os objetivos de aula, e envolver os alunos (o professor a que se refere parece-nos aquele professor profissional, cuja credencial é de fato essa - sua profissão), é aquele que não faz apenas uso dos recursos plausíveis disponíveis para ensinar o conteúdo. Outrossim, é aquele professor que busca com paciência, resiliência e alegria todos os meios para ensinar e transmitir algo, até que atinja e envolva o aluno. Numa leitura mais extensiva e interpretativa, essas parecem ser as características de um professor virtuoso, que é frequentemente citado em seus escritos.

Isto posto, será possível estabelecer uma concreta relação entre esses postulados do educador checo e as práticas contemporâneas de educação inovadora? É ao que nos propomos fazer a seguir.

\section{Relato de experiência: Comenius, um teórico da educação apresentado sob o olhar de práticas inovadoras}

Reiterando, a disciplina na qual nasceu a proposta deste estudo, Teorias da Educação e Formação de Professores, tem por intuito apresentar as ideias e contribuições para a área dos mais renomados e conhecidos educadores clássicos. Dentre os inúmeros nomes nesse campo, foram escolhidos para aprofundamento, totalizando onze, os seguintes teóricos: Jan A. Comenius, Jean-Jacques Rousseau, Jean Piaget, John Dewey, Antonio Gramsci, Lev Vygostsky, e a nível nacional Lourenço Filho, Anísio Teixeira, Fernando de Azevedo, Paulo Freire e Dermeval Saviani.

A organização da disciplina se deu por meio de seminários, realizado por equipes. No caso em questão, a equipe responsável pelo teórico Jan Amos Comenius foi composta por três mestrandos e dois doutorandos em educação, com área de concentração em formação de professores.

A partir das pesquisas e leituras feitas do e sobre o teórico em estudo, e das discussões entre os membros da equipe, percebeu-se de pronto as relações existentes entre as ideias de Comenius à época e as discussões atuais sobre educação inovadora. Destarte, foi proposto que se trabalhasse o seminário por meio de um exemplo de metodologia ativa: a sala de aula invertida ou flipped classroom, que faz parte do modelo de rotação existente no ensino híbrido (HORN e STAKER, 2015). Nessa proposta, o grande objetivo era apresentar aos alunos determinados saberes por meio de estratégias diferenciadas, visto que esse tipo de metodologia tem sido muito difundida e aplicada desde a Educação Básica ao Ensino Superior.

Mattar (2017) reforça que para que haja a inversão da sala de aula é necessário considerar que a aprendizagem também seja invertida, embasado em quatro pilares: ambiente flexível, cultura da aprendizagem, conteúdo intencional e educador profissional. Quando se pensa em uma estratégia como essa é necessário "deixar claro para os alunos o que se espera que façam antes, durante e depois das aulas, os objetivos de cada fase do estudo, os recursos que devem acessar [...] e assim por diante" (MATAR, 2017, p. 34). 
Para que esses pilares fossem pensados e estruturados e, assim, a metodologia fosse aplicada, foi criado um livreto intitulado Comenius e a Didática Magna, versando sobre a vida e obra desse educador, com as principais ideias e discussões teóricas que viriam a embasar a aula, enviado com antecedência aos demais alunos da turma por email e um vídeo animado usando a ferramenta Powtoon3, permitindo que tivesse um resumo de todo o conteúdo de maneira lúdica e animada.

Esse envio antecedente é uma característica dessa metodologia, pois:

\begin{abstract}
Na sala de aula invertida há uma inversão dos trabalhos desenvolvidos pelos os alunos. Na metodologia tradicional o primeiro contato com o conteúdo é em sala de aula através da exposição do tema pelo professor e depois, em casa, os alunos aprofundam e exercitam o tema. Na sala de aula invertida o aluno estuda o tema da aula em casa, por material disponibilizado pelo professor, e no encontro o professor e os alunos socializam a aprendizagem (ALMEIDA; MELO, 2017, p. 4)
\end{abstract}

A leitura antecipada faz com que o momento em sala de aula seja melhor aproveitado e que haja um maior debate de ideias entre os participantes. Comenius, dentro da Didática Magna, aponta que o ensino deve implicar apreciação, envolvimento de ambos, professores e alunos, não de maneira superficial, mas de maneira cabal, contemplando todos os aspectos de um determinado objeto. Isso talvez acarrete o entendimento de que é necessário apresentar o conteúdo ao aluno mais de uma vez, de várias e diferentes maneiras.

Outra estratégia usada foi que, além do material de envio aos demais alunos, no dia da apresentação, a equipe montou a sala como um ambiente flexível, reorganizando os alunos para que pudesse acomodar e apoiar o trabalho em grupo. Outrossim, a apresentação ocorreu com uma inversão da cultura de aprendizagem, na qual os alunos também participaram e debateram sobre a vida e obra do teórico, relacionando suas ideias com o âmbito educacional, com ênfase no ensino superior da contemporaneidade.

É possível nessa estratégia fazer uma correlação dos postulados de Comenius e as metodologias ativas, visto que o autor prezava e considera que os ambientes da escola fossem um espaço onde os professores ensinassem menos e os alunos aprendessem mais. Com base nessa ideia, Diesel, Baldez e Martins (2017, p. 268) descrevem que "enquanto o método tradicional prioriza a transmissão de informações e tem sua centralidade na figura do docente, no método ativo, os estudantes ocupam o centro das ações educativas e o conhecimento é construído de forma colaborativa".

Ao final da aula, como técnica de fixação do conteúdo abordado, apresentou-se uma estratégia diferenciada visando avaliar o nível de aprendizado, bem como reforçar a aprendizagem centrada de maneira ativa no aluno. A estratégia aplicada foi um quiz, utilizando o recurso tecnológico Kahoot! 4 , aplicado aos grupos formados na sala, que conteve sete questões acerca do material enviado com antecedência, dos debates ocorridos na sala e das explanações dos alunos-apresentadores.

Esse tipo de estratégia também vai ao encontro das ideias da sala de aula invertida, pois, como reforça Mattar (2017, p. 38), "os alunos podem ser convidados a realizar atividades e avaliações online depois das aulas, para verificar se os objetivos da

3 Software de animação, fundado em 2012 e baseado na Web, que permite aos usuários elaborar apresentações animadas, manipulando objetos pré-criados e imagens importadas, fornecendo música e narrações produzidas pelo usuário. Essa ferramenta é disponibilizada na versão gratuita e paga.

4 Kahoot! é uma plataforma de elaboração de questionários, pesquisas e quizzes. Criado em 2013, baseado em jogos com perguntas de múltipla escolha, permite aos usuários (especialmente professores e alunos) investigar, criar, colaborar e compartilhar conhecimentos, funcionando em qualquer dispositivo tecnológico conectado à Internet. 
aula foram cumpridos e se estão dominando os conceitos praticados em aula", além de aplicar os princípios da gamificação, de forma que a aula fique mais dinâmica, envolvente e divertida (COSTA et al., 2017).

Bem como também se correlaciona com Comenius quando ele considera que educar para vida é relacionar os conteúdos escolares com o cotidiano, e ações como essa fazem com que os alunos associem o processo de ensino-aprendizagem com situações do dia-a-dia, como um jogo, por exemplo, ritual praticado por muitos diariamente.

\title{
[...] Para gerações acostumadas a jogar, a linguagem de desafios, recompensas, de competição e cooperação é atraente e fácil de perceber. Os jogos colaborativos e individuais, de competição e colaboração, de estratégia, com etapas e habilidades bem definidas se tornam cada vez mais presentes nas diversas áreas de conhecimento e níveis de ensino (MORÁN, 2015, p. 18).
}

Percebe-se assim, que a personalização que foi proposta nesta apresentação, permitiu que a equipe e alunos pudessem refletir sobre um pensador do século XV, relacionando-o aos dias atuais, bem como permitiu um movimento de construção de conhecimento, fazendo sentido para cada um. Bacich e Moran (2018) reforçam esse pensamento quando descrevem que

\begin{abstract}
A ênfase na palavra ativa precisa sempre estar associada à aprendizagem reflexiva, para tornar visíveis os processos, os conhecimentos e as competências do que estamos aprendendo com cada atividade. Ensinar e aprender tornam-se fascinantes quando se convertem em processos de pesquisa constantes, de questionamento, de criação, de experimentação, de reflexão e de compartilhamento crescentes, em áreas de conhecimento mais amplas e em níveis cada vez mais profundos (p. 3).
\end{abstract}

O professor é responsável por auxiliar e motivar o aluno diante do processo de aprender. Nessa perspectiva, pode-se verificar que a proposta de relacionar as ideias de Comenius com as metodologias ativas foi muito mais do que teórica, pois, além de vislumbrar as relações nos escritos antigos e atuais, pode-se aplicar tipos de metodologias ativas, fazendo com que os alunos, em especial, nesse caso se tratando de futuros professores, pudessem entender na prática como se dá a aplicação de um tipo de metodologia ativa.

Comenius chama a atenção do leitor da Didática Magna antevendo que a busca por recursos didáticos disponíveis nas artes, ciências, ou quaisquer outras áreas devem acontecer em todas as escolas, e principalmente nas universidades de onde a produção dos grandes avanços humanos e culturais deve nascer (COMENIUS, 2012). Logo, acreditando que ainda há muito o que fazer quando se fala em educação inovadora e em processos de ensino-aprendizado ativos, criativos e invertidos, devemos estimular o emprego de metodologias ativas, a fim de proporcionar métodos educativos mais efetivos.

\section{Considerações Finais}

Ao final dessa discussão é iminente notar, ao adentrar no campo dos teóricos da educação, a possibilidade de estabelecer relações concretas entre o pensamento já manifesto no séc. XVII por Comenius, com as ideias vigentes e discutidas hoje sobre metodologias ativas e a necessidade de um ensino inovador. Através dessa relação, reafirma-se o quão necessário é discutir educação, formação de professores e didática, sendo estes três pilares que se complementam e são debatidos desde um período em que não se pensava estruturalmente acerca disso.

A aprendizagem por meio da transmissão é importante, mas a aprendizagem por meio de questionamentos, experimentação e, sobretudo, construção orientada de 
conhecimentos, é mais relevante ainda. Especialmente quando se tem como propósito uma compreensão mais ampla e profunda, e quando se discute novas abordagens no ensino superior (graduação e pós-graduação).

É fato que ainda existem muitos campos ainda a desvelar acerca das discussões de teóricos como Comenius, bem como das metodologias ativas, e nessa análise foi possível perceber que por mais que as ideias de ambos se relacionem, há também pontos de divergências, que merecem, por sua vez, análises. Para exemplificar, segundo este autor, o ato educativo tinha como ponto central a figura do professor. Embora este agisse em função da formação do aluno, era a sua prática a principal responsável pela efetivação do aprendizado. No que tange às metodologias ativas, contudo, esse papel de protagonista fica para o aluno, cabendo ao professor orientá-lo e direcioná-lo da melhor maneira, a fim de que o mesmo atinja, construa e desenvolva seus conhecimentos com autonomia.

$\mathrm{Na}$ realidade, considerando as aproximações e divergências que são próprias de pensamentos em épocas diferentes, para fins de fornecer algumas conclusões a partir dessa discussão, é válido mencionar a importância desse tipo de experiência no ensino superior, para que contribua ativamente na formação do professor, mostrando-lhe a concretude das metodologias ativas no ensino. Parece-nos que uma das melhores maneiras de ensinar ainda é pelo exemplo, i.e. usar as metodologias ativas no ensino superior e não experimentá-las na prática debela a efetividade das manifestações de educação inovadora e inviabiliza, e até podem frustrar, o ensino-aprendizagem.

Finalmente, acredita-se que a experiência de empregar as metodologias ativas no campo das teorias da educação, foi enriquecedora e com considerável potencial de transformação.

\section{Referências}

ALMEIDA, Andrea Chagas Alves de Almeida; MELO, Ana Flávia Beviláqua. Flipped Classroom como estratégia metodológica para Educação Superior: Um caso da AnBar Organização de Eventos. In: $\mathbf{2 3}^{\circ}$ CIAED - Congresso Internacional ABED de Educação a Distância, 2017, Foz do Iguaçu - PR.

ARANHA, Maria Lúcia de Arruda. História da Educação e da Pedagogia: geral e Brasil. - 3. ed. - rev e ampl. - São Paulo: Moderna, 2006.

BACICH, Lilian; MORÁN, José. Metodologias ativas para uma educação inovadora: Uma abordagem teórico-prática. Porto Alegre: Penso, 2018.

BERBEL, Neusi Aparecida Navas. As metodologias ativas e a promoção da autonomia de estudantes. Semina: Ciências Sociais e Humanas, Londrina, v. 32, n. 1, p. 25-40, jan./jun. 2011.

COMENIUS, Jon Amós. The great didactic of John Amos Comenius. Editora: Leaf.com books. Versão Kindle. Publicado em 2012. ISBN versão kindle: B009XJ5E3W. ISBN versão impressa: 1169351085.

COSTA, Alex Felipe Ferreira; de MELO, Alex Frederico Mathias Felix; MOREIRA, Gabriel Gonçalves, CARVALHO, Marcos de Alencar; LIMA, Marcos Vinícius de Andrade. Aplicação de Sala Invertida e Elementos de Gamificação para Melhoria do Ensino-Aprendizagem em Programação Orientada a Objetos. In: TISE 2017 - XXII Conferência Internacional sobre Informática na Educação, 2017, Fortaleza. 
DAMIS, Olga Teixeira. Didática e Ensino: Relações e Pressupostos. In: VEIGA, Ilma Passos Alencastro (coord). Repensando a Didática. - 29a ed. - Campinas, SP: Papirus, 2012.

DIESEL, Aline; BALDEZ, Alda Leila Santos; MARTINS, Silvana Neumann. Os princípios das metodologias ativas de ensino: uma abordagem teórica. Revista Thema. Instituto Federal de Educação, Ciências e Tecnologia Sul-rio-grandense. Pelotas, RS, Brasil, v. 14, n. 1, p. 268-288, 2017.

HORN, Michael B; STAKER, Heather. Blended: usando a inovação disruptiva para aprimorar a educação. Porto Alegre: Penso Editora, 2015.

FILATRO, Andrea; CAVALCANTI, Carolina Costa. Metodologias Inov-ativas na educação presencial, a distância e corporativa. São Paulo: Saraiva Educação, 2018.

NUNES, Ana Ignêz Belém Lima; NUNES, João Batista Carvalho. Papel dos formadores, modelos e estratégias formativos no desenvolvimento docente. SérieEstudos (UCDB), v. 36, p. 91-108, 2013.

MATTAR, João. Metodologias Ativas: Para a educação presencial, blended e a distância. São Paulo: Artesanato Educacional, 2017.

MORÁN, José. Mudando a educação com metodologias ativas. In: SOUZA, Carlos Alberto de; MORALES, Ofelia Elisa Torres (orgs.). Coleção Mídias Contemporâneas. Convergências Midiáticas, Educação e Cidadania: aproximações jovens. Vol. II. PG: Foca Foto-PROEX/UEPG, 2015.

WALKER, Daniel. Comenius - O Criador da Didática Moderna. Edição do Kindle. 